\title{
Power Customer Resource Value Evaluation Model Based on TOPSIS and Grey Correlation Degree Method Under Background of Power Sales Side Market Liberalization Tianqiong Chen ${ }^{a}$, Song Xue ${ }^{b^{*}}$, Hongxian Zhang ${ }^{b}$, and Ming Zeng ${ }^{c}$ \\ ${ }^{a}$ State Power Economic Research Institute, Changping District, Beijing 102209, China \\ ${ }^{\mathrm{b}}$ State Grid Energy Research Institute, Changping District, Beijing 102209, China \\ c State Key Laboratory of Alternate Electrical Power System with Renewable Energy Sources, North China Electric Power University, Changping District, Beijing 102206, China \\ *Corresponding author: Song Xue, Doctor of Administration, xuesongbjhd@163.com
}

\begin{abstract}
In the future the electricity selling companies need to evaluate customer resource value scientifically and rationally for improving profitability. This paper analyzes the connotation of power customer resource value, divided into the current value and potential value. It evaluates the current value according to power customers' financial situation, the level of purchase, electrical characteristics and evaluates the potential value through the power customer credit status, power customer development potential, building a power customer resource value evaluation index system containing 46 four level segment indexes. In order to improve the rationality of giving weight to various factors, it constructs TOPSIS comprehensive evaluation method based on gray correlation degree optimization, evaluating the customer resource value to provide support for the electricity selling companies making decision.
\end{abstract}

Key words: power sales side market liberalization; power customer resource value; TOPSIS Comprehensive Evaluation Based on Gray Correlation Optimization

\section{Introduction}

Side of electricity sale reform of is one of the key tasks of Chinese a new round of electricity market reform which will gradually open up the user options, build multiple electricity selling companies forming a "multi-buyer - multi-seller" market. It's urgent to build power customer resource value evaluation model in the future for the purpose of helping electricity selling companies to identify high-value customers correctly, providing differentiated services and value-added services, allocating limited resource of enterprises rationally and maximizing the corporate economic benefits and social benefits on the basis of improving the service management level.

This paper analyzes the connotation of power customer resource value. The purpose of customer resource value evaluating management is to compare customers, rather than calculate the value of a particular customer accurately, which is difficult to calculate specifically. For this reason this paper constructs power customer resource value evaluation index system containing the customer current value and potential value. It for the evaluation system of qualitative and quantitative characteristics, in order to improve the rationality of giving weight to various factors, using gray correlation to improve the TOPSIS method, evaluating the closeness between the client and the ideal customers comprehensively, rating the samples according to the closeness, providing basis for decision making. 


\section{Evaluation index system of power customer resource value}

\subsection{The connotation of power customer resource value}

The customer resource value in electric power industry is a comprehensive concept which is the comprehensive interests for electricity companies from customers in the overall customer life cycle, specifically including two aspects which are power customer current value and power customer potential value ${ }^{1}$.

(1)power customer current value

The power customer current value is under customer business status and purchasing behavior keeping constant, the size of customer value for electricity selling companies. Factors that influence customer current value are profit, stability and operating status, operating capacity, credibility, social relations and so on.

(2)power customer potential value

Power customer potential value is assuming that electricity selling companies adopted a more positive customer retention strategy, so that customers buying behavior develop in the direction of increasing the profit of power supply enterprises, customers in the future would be expected to supply power enterprise current value of the sum of the profit. This part is an estimate of customer potential value, described as "customer value-added potential". Customer value-added potential depends on the probability of customers incremental and crossover purchasing.

\subsection{Framework of power customer resource value evaluation index system}

Considering that it is difficult to include all the quantitative or qualitative factors, even for the most complex model it is impossible to accurately quantify the value of customer, and the more complex computation the cost is higher. For this purpose, it intends to use index evaluation method assessing customer resource value.

Customers' current value focused on the customer's current monetary value, namely customer net cash flow generates in the current life cycle in size, so the customer current value could be evaluated by customer profitability. Customer potential value includes customer loyalty, satisfaction, cost savings, customer recommendation, technical progress, image promotion, management improvement, supply chain integration and so on, generally using customer lifetime value to calculate. From the short term interests, the electricity selling companies hope to choose the customers who have maximum current value and can bring maximum cash flow for enterprise, while from the long-term perspective, the electricity selling companies must enhance customer loyalty and improve management, meaning to get help from those customers with greater potential value. But sometimes they are unified, customers who has high current value and potential value, will become the enterprise's core customers getting enterprise's management and service focus, will also be the main source of corporate profits and the factors taken into account for making strategic decisions.

According to the above theory, this paper proposes to regard the power customer value as the first level index, studied from two second level indexes the power customer current value and future potential value. Then decompose second level indexes into third level indexes, among which the power customer financial situation, purchasing level, consumption characteristics are used to evaluate current value and power customer credit status and development potential 


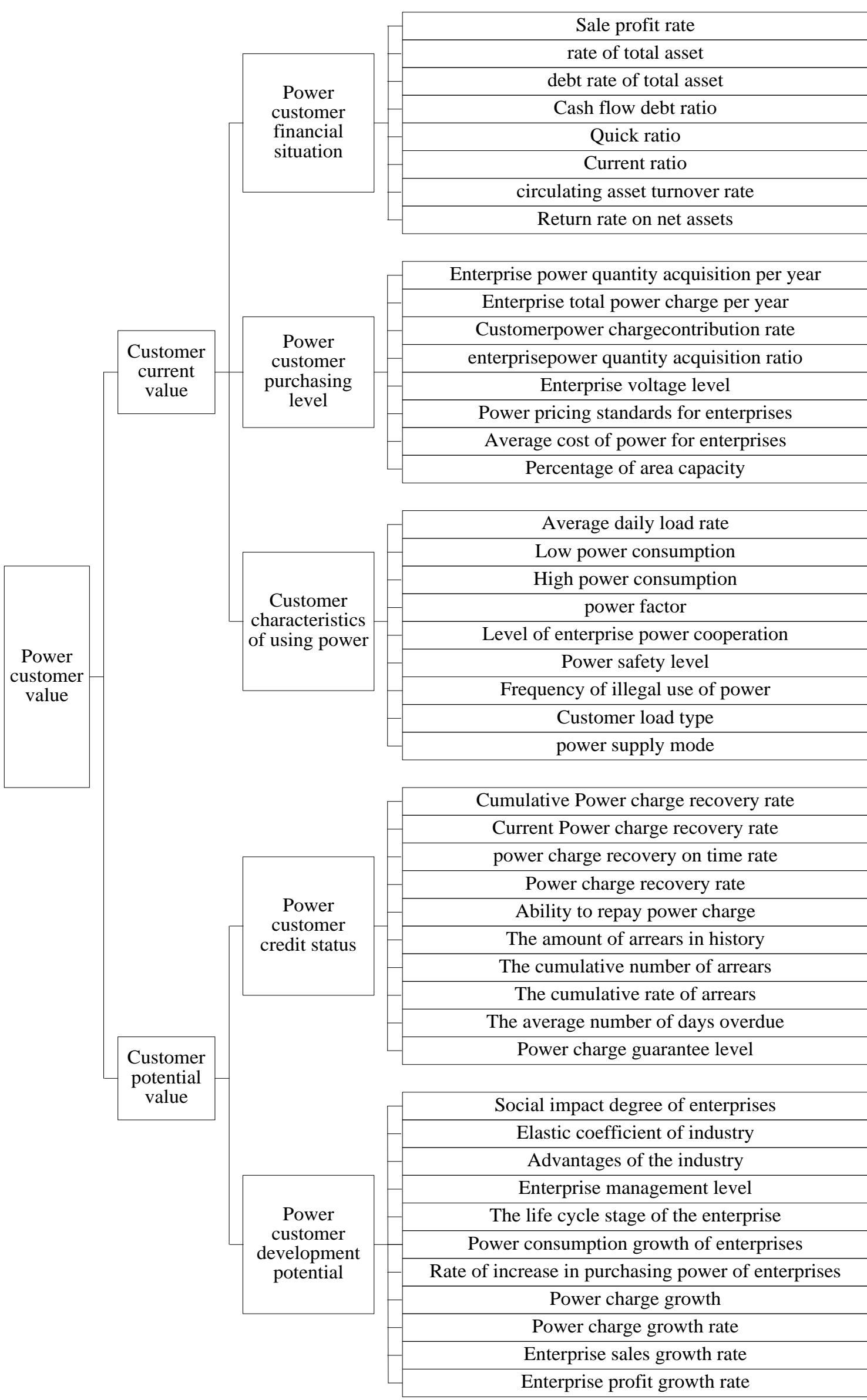

Figure 1 Power customer value and the overall index system 
are used to evaluate the potential value. This paper lists 46 fourth level subdivision indexes to assess the power customer value and the overall index system are shown in the Figure $1^{2}$.

\section{Comprehensive evaluation method of power customer resource value}

According to the evaluation index system of power customer resource value, various factors are given reasonable weight. The building principle of the comprehensive evaluation method is to guarantee rationality and effectiveness of the evaluation system. TOPSIS is an ideal sorting method, which has been used for the project investment's risk evaluation, project sample selection, etc. Using grey relational to improve TOPSIS ${ }^{3}$, it can more exactly descript the closeness degree between to be evaluated customers and ideal customer, and then, prioritize the sample and provide decision-making basis.

(1)Build index matrix

Suppose to evaluate $\mathrm{m}$ samples containing $\mathrm{n}$ evaluation indexes, corresponding to each index value is $r_{i j}(\mathrm{i}=1,2, \ldots, \mathrm{m} ; \mathrm{j}=1,2, \ldots, \mathrm{n})$. Their index matrix is $R=\left(r_{i j}\right)_{m \times n}$.

$$
R=\left[\begin{array}{ccc}
r_{11} & \cdots \cdots & r_{1 n} \\
\vdots & \cdots \cdots & \vdots \\
r_{m 1} & \cdots \cdots & r_{m n}
\end{array}\right]
$$

(2) Normalized index matrix

Owing to the different natures of evaluation indexes, there are large differences among some indexes' units and scales, and the corresponding index values also have great differences. For ease of comparison, normalization process of the index matrix should be done.

$$
x_{i j}=r_{i j} /\left(\sum_{i=1}^{m}\left(r_{i j}\right)^{2}\right)^{1 / 2}
$$

The new dimensionless index matrix $X=\left(x_{i j}\right)_{m \times n}$ is obtained after normalizationprocess.

(3) index weight determination

The weight of each index is determined by the entropy weight method. According to the definition of entropy, calculate the entropy value of $j$ customer resource index:

$$
\begin{aligned}
& h_{j}=-\frac{1}{\ln m} \sum_{i=1}^{m} p_{i j} \ln p_{i j} \\
& p_{i j}=\left(1+x_{i j}\right) / \sum_{i=1}^{m}\left(1+x_{i j}\right)
\end{aligned}
$$

The number i index's entropy weight of customer resource value is:

$$
w_{j}=\left(1-h_{j}\right) / \sum_{j=1}^{n}\left(1-h_{j}\right)
$$

The column vector of index weight is:

$$
W=\left(w_{1}, w_{2}, \cdots, w_{n}\right)^{T}
$$

Where, $w_{i}$ is index weight.

(4) Weighted normalized index matrix

The normalized index matrix multiply corresponding index weights, and then, the weighted normalized matrix $Y$ is obtained. 


$$
Y=\left(y_{i j}\right)_{m \times n}=\left(w_{j} x_{i j}\right)_{m \times n}
$$

Secondly, determine the positive ideal solution and the negative ideal solution of evaluation sample, and calculate Euclidean distances and grey relational of the customer resource value index sample and the positive ideal sample and the negative ideal sample.

(5) Determine the positive ideal solution and the negative ideal solution

The maximum and minimum values of each index set are determined respectively. The maximum value of positive indexes and the minimum value of negative indexes compose the positive ideal solution, and the minimum value of the positive indexes and the maximum value of negative indexed compose the negative ideal solution.

$$
\begin{aligned}
& Y_{0}^{+}=\left(\max _{1 \leq i \leq m} y_{i j}\left|j \in j^{+}\right|, \min _{1 \leq i \leq m} y_{l j}\left|j \in j^{-}\right|\right)=\left(y_{1}^{+}, y_{2}^{+}, \ldots, y_{m}^{+}\right) \\
& Y_{0}^{-}=\left(\min _{1 \leq i \leq m} y_{l j}\left|j \in j^{+}\right|, \max _{1 \leq i \leq m} y_{l j}\left|j \in j^{-}\right|\right)=\left(y_{1}^{-}, y_{2}^{-}, \ldots, y_{m}^{-}\right)
\end{aligned}
$$

Where, $j^{+}$is the positive indexes (the value is bigger, it is better), $j^{-}$is the negative indexes (the value is smaller, it is better).

(6) Calculate Euclidean distances between the sample value and positive and negative ideal solutions.

The Euclidean distances between the sample i of customer resource value and the positive ideal solution and the negative ideal solution respectively are $D_{i}^{+}$and $D_{i}^{-}$.

$$
\begin{aligned}
D_{i}^{+} & =\sqrt{\sum_{j=1}^{n} w_{j}\left(y_{i j}-y_{j}^{+}\right)^{2}} \quad(i=1,2, \cdots, m) \\
D_{i}^{-} & =\sqrt{\sum_{j=1}^{n} w_{j}\left(y_{i j}-y_{j}^{-}\right)^{2}} \quad(i=1,2, \cdots, m)
\end{aligned}
$$

(7) Calculate the grey relational of the sample and the positive ideal solution and the negative ideal solution

1) Based on the weighted normalized matrix, it calculates the grey relational coefficient about the number $\mathrm{j}$ index of the sample $\mathrm{i}$ of customer resource value indexes and the positive ideal sample.

$$
\mu_{i j}^{+}=\frac{\min _{i} \min _{j} \Delta y_{i j}+\rho \max _{i} \max _{j} \Delta y_{i j}}{\Delta y_{i j}+\rho \max _{i} \max _{j} \Delta y_{i j}}
$$

Where, $\Delta y_{i j}=\left|y_{j}^{+}-y_{i j}\right|$, $\min _{i} \min _{j} \Delta y_{i j}$ is two levels of minimum differential, $\max _{i} \max _{j} \Delta y_{i j}$ is two levels of maximum differential. $\rho \in[0,1]$, and it is resolution coefficient, generally values 0.5 . The grey relational coefficient matrix of each sample and the positive ideal sample is:

$$
V^{+}=\left[\begin{array}{cccc}
\mu_{11}^{+} & \mu_{12}^{+} & \cdots & \mu_{1 n}^{+} \\
\mu_{21}^{+} & \mu_{22}^{+} & \cdots & \mu_{2 n}^{+} \\
\vdots & \cdots & \cdots & \vdots \\
\mu_{m 1}^{+} & \mu_{m 2}^{+} & \cdots & \mu_{m n}^{+}
\end{array}\right]
$$

The grey relational of the sample $i$ of customer resource value indexes and the positive ideal sample is:

$$
V_{i}^{+}=\frac{1}{n} \sum_{j=1}^{n} \mu_{i j}^{+}, \quad(i=1,2, \cdots, m)
$$


2) Calculate the grey relational coefficient about the number $j$ index of the sample $i$ of customer resource value indexes and the negative ideal sample.

$$
\mu_{i j}^{-}=\frac{\min _{i} \min _{j} \Delta y_{i j}+\rho \max _{i} \max _{j} \Delta y_{i j}}{\Delta y_{i j}+\rho \max _{i} \max _{j} \Delta y_{i j}}
$$

Where, $\Delta y_{i j}=\left|y_{j}^{-}-y_{i j}\right|$. The grey relational coefficient matrix of each sample and the negative ideal sample is:

$$
V^{-}=\left[\begin{array}{cccc}
\mu_{11}^{-} & \mu_{12}^{-} & \cdots & \mu_{1 n}^{-} \\
\mu_{21}^{-} & \mu_{22}^{-} & \cdots & \mu_{2 n}^{-} \\
\vdots & \cdots & \cdots & \vdots \\
\mu_{m 1}^{-} & \mu_{m 2}^{-} & \cdots & \mu_{m n}^{-}
\end{array}\right]
$$

The grey relational of the sample i of customer resource value indexes and the negative ideal sample is:

$$
V_{i}^{-}=\frac{1}{n} \sum_{j=1}^{n} \mu_{i j}^{-}, \quad(i=1,2, \cdots, m)
$$

Finally, according to the calculation of the relative closeness degree, achieve the sample sorting and optimization.

(8) Dimensionless process of Euclidean distance and grey relational

$$
\phi_{i}=\frac{\Phi_{i}}{\max _{1 \leq i \leq m}\left(\Phi_{i}\right)} \quad(i=1,2, \cdots, m)
$$

Where $\Phi_{i}^{-}$represents ${ }_{D_{i}^{+}}, D_{i}^{-}, V_{i}^{+}, V_{i}^{-} \cdot d_{i}^{+}, d_{i}^{-}, v_{i}^{+}$and $v_{i}^{-}$are the values after dimensionless process.

(9)Comprehensively consider Euclidean distance and grey relational after dimensionless process

The values of $d_{i}^{-}$and $v_{i}^{+}$are bigger, the sample is closer to ideal solution; the values of $d_{i}^{+}$and $v_{i}^{-}$are bigger, the sample is more deviation of the ideal solution. Comprehensively consider Euclidean distance and grey relational after dimensionless process:

$$
\begin{aligned}
& R_{i}^{+}=a_{1} d_{i}^{-}+a_{2} v_{i}^{+} \quad(i=1,2, \cdots, m) \\
& R_{i}^{-}=a_{1} d_{i}^{+}+a_{2} v_{i}^{-} \quad(i=1,2, \cdots, m)
\end{aligned}
$$

Where, $a_{1}$ and $a_{2}$ reflect the preference of decision makers on location and shape, and $a_{1}+a_{2}$ $=1$. Decision makers can determine the value of $a_{1}$ and $a_{2}$ based on their preferences. $R_{i}^{+}$and $R_{i}^{-}$ reflect the closeness degree of customer resource value index samples and the positive ideal solution and the negative ideal solution.

(10) Calculate the relative closeness degree

The relative closeness degree reflects the closeness about the tendency of the sample and the positive ideal solution or the negative ideal solution.

$$
\delta_{i}=\frac{R_{i}^{+}}{R_{i}^{+}+R_{i}^{-}} \quad(i=1,2, \cdots, m)
$$

Where, $\delta_{i}$ is relative closeness degree.

(11) Sample sorting

According to the calculation results of formula (21), sort the samples based on the size of $\delta_{i}$. $\delta_{i}$ is bigger, sample of to be evaluated customer resource value is closer to the positive ideal 
sample, and the sample is superior; on the contrary, $\delta_{i}$ is smaller, sample of to be evaluated customer resource value is closer to the negative ideal sample, and the sample is inferior.

\section{Conclusion}

Value that customer brings to enterprise is evaluated through a series of technical means, identifying customers who have greater probability to maintain relationship with the enterprise, and then enterprise provides different service resource to them. Service management level is improved, and meanwhile the profitability of enterprise is enhanced. Therefore, after the electricity sell-side opening in the future, the customer knowledge management data center needs to be established in the process of applying customer resource value evaluation model, to improve application efficiency and effect of the model.

\section{Acknowledgements}

The work described in this paper was supported by Science and technology projects of State Grid Corporation (No. SGERI06KJ [2015]63).

\section{References}

1. Z. Ming, Zhang J., Li H., Intelligent Electricity Marketing System for Smart Grid, J. East China Electron Power. 5(2012) 703-707.

2. M.Zeng, Research on the construction scheme of power marketing customer intelligence system. Kunming: Kunming Power Supply Bureau, 2010 122-140.

3. M.Zeng, J. Feng, Z. Wang, Study on life cycle investment risk evaluation of wind power projects, J. IcIc Express Lett. Part B, 5(2014) 1051-1056. 